\title{
Discussing about the Dialectical Relationship between Knowledge and Mentality
}

\author{
Duong Thi Huong* \\ University of Economics and Business Administration, Thai Nguyen University, Thai Nguyen, Vietnam \\ *Corresponding author: huongnguyenthai26@gmail.com
}

Received March 08, 2018; Revised April 15, 2018; Accepted April 18, 2018

\begin{abstract}
In this day and age, knowledge has became the best and most important resource for creating breakthrough development of each country; the answer to the great power of science and technology revolution in the development of the world. From analyzing the concepts of knowledge and mentality, the study makes clear the dialectical relationship between knowledge and mentality. In the relationship, knowledge and mentality precribe and control the development of one another. Knowledge is the basis for the development of mentality, mentality is considered to be the motivation for creating of new knowledge, and developing it on higher level in perception of the objective world. Knowledge is the determining factor of the development of mentality. From the above study, the author drew on the meaning of methodology for development strategies, enhancing the competitiveness of countries and quickly adapting to changes of knowledge economy.
\end{abstract}

Keywords: knowledge, mentality, knowledge economy, the relationship between knowledge and mentality, mentality development

Cite This Article: Duong Thi Huong, "Discussing about the Dialectical Relationship between Knowledge and Mentality.” American Journal of Educational Research, vol. 6, no. 5 (2018): 436-442. doi: 10.12691/education-6-5-11.

\section{Introduction}

Nowadays, knowledge has became the universal resource for the development of each country. In some studies, the authors recognized the role of knowledge and intellectuals $[1,2,3,4]$. Appreciating the role of education and trainning in development of knowledge, the authors Dang Huu [5] and Phung Danh Cuong [6], claimed that education and training help human resources in equipping knowledge and creative thinking abilities and innovation, is the basis for the development of mentality to meet requirements of knowledge economy.

Discussing the role of knowledge in the respect of brainpower resources: Bui Van Hue [7], Pham Hong Tung and Pham Ngoc Thach [8], Pham Thai Viet [9], Bui Thi Ngoc Lan [10], Vu Dinh Cu [11], Hoang Van Luan [12], Pham Minh Hac [13], Nguyen Van Khanh [14]; Ngo Thi $\mathrm{Nu}$ [15], emphasized the role of brainpower as an important resource to create the most basic motivation for break-through development of the country. In those studies, brainpower is considered to be the combination of the relationship between knowledge and creativity in perception and practices. The concept of mentality is constructed as a mental power, based on knowledge. The authors put a dialectical relationship between knowledge and mentality in the totality of brainpower resource and tend to emphasize the role of knowledge to mentality, but did not focus on the influence of mentality on knowledge.

The Truong [16], Tham Vinh Hoa and Ngo Quoc Dieu [17], Dang Tieu Binh [18] have further studies on the relationship between knowledge and mentality but are scattered, due to the purpose of studies and studies did not have the means to study systematically this issue.

The study of the dialectical relationship between knowledge and mentality is one of the most important studies, because it is the answer to the question of why knowledge has became the best and the most important resource for break-through development of each country; the answer to the power of the science and technology revolution in the contemporary world.

\section{Content}

\subsection{Concepts of Knowledge and Mentality}

- A concept on Knowledge

Knowledge is a product of human intelligence. The difference between human and animal lays on the experiencing ability and knowledge form. With the process of understanding, collecting, transferring and using knowledge in practical, human reached on peak of intelligence.

In ancient time, Plato, though with improper concept on knowledge source, laid emphasis on knowledge role of philosophers and scholars and nominated them for the highest position in the government. Democritus, a wellknown materialism philosopher, considered peak of human happiness as an achievement of scholar level that has controllability of intelligence and spirit. Moreover, according to him, "a life without intelligence, balance and fault is not a bad life, but a gradual death” [[19], p.213]. 
Aristotle had a proper concept which assumes reflected object as first existence, and the knowledge of such object comes following. His work Metaphysics was opened by the famous argument: everyone, in their nature, desires knowledge. Under his view, science is a complex system of knowledge.

Turning into the Renaissance and Modern time, F.Bacon, the pioneer of Britain Materialism and founder of experimental science, argued that knowledge is the power without which human have no way to possess natural assets. Thus in his time, he integrated knowledge with labor, an element of agriculture economy. He defined position of knowledge in the agriculture economy and set a background for the argument of knowledge position in the new economy - industry.

Even from 1982, C. Mac made an early alarm for danger of lacking knowledge. He pointed out: "Unawareness is evil power and, in our worry, cause of other tragedies." With talented prediction, C. Mac made an advanced forecast on the significant role of science 00knowledge for modern society. Moreover, he figured out that in the coming future, science knowledge would turn into the direct producing force.

In Vietnamese words, the term "Tri thức” (Knowledge) is constituted from two single sino-characters "Tri" and "thúc". "Tri" (understanding) consists of three main meanings: in noun form it means "tri thíc" (knowledge); in verd form means "biết" (knowing); and in pronoun form "trí”, "trí tuệ", "trí thông minh" (understanding, intelligence or mental ability) [[16], p.26]. “Thúc” in its original meaning is a skill of a weapon, such as sword or spear, to battle producing noise of break by which someone knows that their is a fight happening. Not hearing you can not know, in hearing you can know; similarly, not telling you can not understanding, in telling you can understand quickly and clearly [[16], p.27]. Thus, knowledge means the perception of what you knew and understanding it more exactly and deeper.

In the book "Vietnamese Dictionary", Institute for Linguistics defines: "knowledge is a system of understandings on things or circumstances happening in nature or society" [[21], p.1032]. Ministry of Traing and Education, Vietnamese Language and Culture Center, Complete Vietnamese Dictionary, defines: "Knowledge is a system of understandings on general things" [[22], p.1074]. Such definitions focus on understandings collected from perception activities, not mention creativeness, science and experiment aspects of knowledge.

Definitions considering knowledge as product of perception process and practical activities, correctly reflecting objective reality under practical verification: "Knowledge derives from perception of reality verified under experiment, and is correct reflection of reality inner human thought” [[16], p.22]; "Knowledge is the complete mixture of perception and experiences collected through real world improvement process" [[16], p.22]; "Knowledge is the product of social working activities and human thinking which is reproduced under language and objectives relationships in accordance with principles of the objective world which undertakes an practical improvement" [[23], p.596-597]; Such definitions, however, fail to mention the creativeness and newness of knowledge during perception process and practical activities of human.
Some studies, with unusual approaches on knowledge, has clearer described creative element of knowledge: "Knowledge derives from human perception against real world, and reflect into thought attributes and rules of such world, and present them by language or any other system of script" [[24], p.471]; "Knowledge is the result of human perception and practical activities in which including process of experiencing, studying, understanding, communicating and arguing etc. Knowledge is the measure for creativeness, activeness, but in a more exactly speaking, all concepts exist under knowledge. Knowledge appeared itself as a objective form of thought for each and every kind of operation and communication. It is a means to transfer symbol system, concepts, activities and communications, appying on them a new form, also new meaning. Knowledge appears as thought of human on their experimental situations" [[14], p.33]. Here, the composer pointed out the new form of knowledge "which is the means of trasferring symbol system, concepts, activities and communications, appylying on them a new form, also new meaning” - knowledge of knowledfe creativeness

Alvin Toffler, a futurologist, claimed that knowledge includes: "conditions such as assumption, value, picture, inspiration and exact technical ability" [[25], p.316]. Sometimes he said: "High technique is knowledge solided" [[26], p.296]. However, in expansion implicity of knowledge, he added: "What called basic knowledge is not necessary to be science technology or any conventional education idea. It covers strategy concept of a country, forming foreign intelligence execution, understanding basically culture of other countries, culture and perception impacting on countries, together with new concepts, new information and new imagination which achive the level of trasferring" [[26], p.480]. In traditional concepts, we see that science knowledge is human perception on the common picture of objective world, knowledge prove level of perception and control natural world of human. However, the viewpoint of Alvin Toffler gives us a new concept of knowledge which is not only the creativeness in science, new inventions of science and technology as said "technique is knowledge solidified", but also bears practical values meeting practical conditions for development of a country, forming foreign intelligence executive system. Alvin Toffler not only discussed role of knowledge as a product of human thinking upon nature, society and themselves, but also emphased its practical property and role, and compatibility of knowledge for real conditions of socio-economy, meeting development demand of a country.

In his viewpoint, Alvin Tofller also pointed out importance of knowledge - "revolutionary property". He wrote: "It is not the fact that only science or technical knowledge has and will has created remarkable splendid advances. But the fact is that from organisation theory to music, from biological research system to cerebral cortex perception, from language to studying reasoning, from unbalanced form to time of chaos, studying diffusion scheme, no one of them is beyond revolutinary nature" [[26], p.432-433]. This is the Alvin Tofler's new approach on knowledge: "Knowledge of knowledge", that is knowledge is the perception of objective things and circumstances bearing property of creating new 
knowledge based on the initial one from which creating "revolutionary" property for knowledge. Alvin Toffler highlighted new knowledge creation of knowledge. Thank to this property that knowledge can be an assets, development resource for a country, and extreme power origin for the time of science and technology. Alvin Toffler wrote: "Mental assets is the creative efforts of human in the area of science including technical science, art, literature, design and other intagible general knowledge activities. It undertakes development through hyper-symbolized economic model and becomes a tool with value even higher than economy and politics” [[26], p.377]. All power sources, including abundant natural resources, are utimately exhausted but human, because knowledge is an endless source.

To clarify role of knowledge under impact of computing technology, in his works, Alvin Toffler pointed out: under impact of computing network, any perception of knowledge will quickly become obsolescent. He wrote: "Under impact of computing network which creates extreme changes as today: any existed true is subjected to a quick backwardness. And even emerging knowledge can be fast obsolete. To correct usual factors, the scientists first endeavour to establish new organisation and science means in order to accelerate science research and development. It is the way to boost studying process. Replacement old knowledge with new ones happend quicker and quicker” [[26], p.478]. Thus, to align with fast change under impact of computing network, only revolutionary property of knowledge and creativeness can meet demand of acceleration of economy-society and become the unique important resource creating motivation for country development. In his works, Alvin Toffler claimed creativeness role of knowledge in providing significant values for the global economy today. Revolutionary element of knowledge grants knowledge with power in the Third Wave, knowledge become essential economy-boosting element in twenty-first century. Alvil Toffler thus stated: "knowledge is wealth", knowledge can adjust the whole of power structure, and the origin of power in XXI century.

New knowledge is created on the basic material of information. Within viewpoint of Macism, information is a nature of material created during interaction between metarial systems through reflection process. Reflection means reproducing characteristics of one material into another through their interaction. One material system can record information of another under impact process. Thanks to information marks recorded during reflection, new knowledge will be produced. Some scientists present viewpoint of information based on an approach on its role. As a German scientist - E.Pietch - poited out that information is a product in whose meaning and useage is equal to material capacity of the country [[27], p.77]. More general, R.Esbi said: "information is date touchable, understandable and rearrangeale to form knowledge" or "information is the content of outer world which is presented as inner perception of human” (N.Viner) [[27], p.78].

In the work of Power Shift, Alvin Toffler wrote: "Information is represtative for passed adjustment and material classification while knowledge is the conclusion of such information which is converted through additional step to bear an implicit and deep meaning [[25], p.46]. Thus, information is the background of knowledge. Information become early material for people to obtain initial perception on things and circumstances and form knowledge. Information and knowledge become scientific background for perception and decision making of each person in their practical activities. On role of knowledge in the work The Third Wave, Alvin Toffler, the futurologist, pointed out that: information become the most significant material, and objective demand for perception and practical activities of human. In receiving and using information and knowledge for perception and practical activities, each person, each company, each nation in the era of Third Wave will find their key for success - the future civilization of human beings.

Thus, present knowledge issue has gone beyond coverage of Gnoseology and experiment area to become a practical means, a creative instrument and special origin of the highest power in the future, "New knowledge is the key to unlock the power gate of XXI century” [[25], p.30], the supreme power lays on knowledge. We can understand as following: Knowledge is the result from the process of receiving and treating information in a creative manner, knowledge reflects objective reality through human mind under forms of concepts, ideas, guesses and arguments which are verified by practical activities, knowledge bears historical and revolutionary elements. It consists of information, date, reasoning background and techniques that an organisation or individual obtain through their perception activities and practical activities, it is the understanding and creation in terms of theory and practice also, an issue integrated with environment changes.

\section{- Concept of mentality}

Mentalty is the key of the capacity, the nucleus for creating energy. Mentality plays an irreplaceable role in developing and demonstrating câpcity. Future society is a kind of mental society. The mentalty will become an important element of the social system. Power and wealth will increase with the development of mentality. Someone believe that "science and technology" is the leading production power, the core part of thought in the knowledge economy, but science and technology is the crystallization of mentality.

The concepts of mentality such as mentality is: "intellectual capacity" [[27], p.1075]; "Mentality is the power of brainpower" [[28], p.826]; is "trying to think, searching with the brain" [[29], p.852], or the author Pham Minh Hac worte: brainpower is "understanding, education, intelligence, mentality - intellectual, knowledge, ingenuity, wisdom, wiseness" [[13], p.826]. These approaches have not shown the difference, or characteristics, manifestations of mentality in the concept of knowledge.

According to the author Nguyen Van Khanh, "Mentality can be understood as brainpower capacity, but mentality especially mental development - can not just be judged through IQ; thus, "mentalty" is not identical with "intelligence" but implies it and tends to be identified with "brainpower" [[14], p.31] - "Brainpower is the combination of cognitive ability and capacity to adapt creatively and effectively to the environment of human" [[14], p.31]. This view shows a deeper understanding of mentality mentality is not only knowledge, creation of new knowledge, but also implies practical ability supports 
individuals to respond and adapt quickly to changes. Therefore, the author did not identify "mentality" with "intelligence" or "brainpower".

The authors, Tham Vinh Hoa and Ngo Quoc Dieu, said that "Mentality is the capacity of human to awareness and improve the objective world, includes: the capacity to scientifically understand the nature and development of nature and society; the capacity of physical thinking on natural and social rehabilitation; the capacity to judge values; the capacity to exploit innovations, and the capacity to control practical activities ... " [[17], p.173-174]. The author has shown the manifestations of mentality and specific capacities of perception, practical activities and has confirmed the development of mentalty is based on knowledge.

Thus, it is possible to understand that the concept of mentality is the capacity of human brainpower in perception and practives. It is also the capacity to find new relationships between information, knowledge, and single and discrete experience. These relationships will create new knowledge and practical adaptive capacity for environmental changes under creative thinking. Creativity is the most important quality of mentality. The product of mentality is: new knowledge, practical ability to adapt to changes in the environment.

\subsection{The Dialectical Relationship between Knowledge and Mentality}

\subsubsection{The Role of Knowlege in the Mentality Development}

Firstly, knowledge is the basis of mentality formation, that it determines the development of the mentality. Historical fact proved that human knowledge is becoming much more rich, human conciousness of objectivity is become much more perceptive as well, the strongger spirit of dealing with problem is, the higher mentality is. The development of productive forces is the human capacity relying primarily on the mentality development. Throughout the history, we have seen that social work forces developed rapidly, which are largely due to the development of mentality, science, culture and education. In the Capital, Marx analyzed in a subtle way: "Nature itself is completely incapable of creating any material wealth source, the wealth are products of the human industry and the mentality materialized" The development of fixed capital showed that: social knowledge, in general, with a quite large extent, became direct production force, besides, the conditions of social production process, with a large extent, were also controlled by knowledge, and based on this knowledge, they transformed" [[17], p.81]. The scientific revolution in the history and industrial one 4.0 in the world nowadays is the mentality revolution, on the basis that the knowlege has the proper amount.

Human mentality was formed not by nature, but by the process of acquiring social, family and school education equipping with knowledge and creative thinking skills that each person adapt to. In fact, genius quality only provides the capacity for mentality development, whether it creates mentality or not, this entirely dependent on the individual absorbing the knowledge through the education environment and self-education process. Thus, in order to exploit mentality, many countries increase their investment in education development, setting the strategy that give priority to mentality. In Dang Tieu Binh's opinion: "Despite a little sacrifice of speed to increase funding for education, as consequent, in a short term, the pace of national economic development will be slow a little bit, but in the long term, this will lead China's economic development gaining the capacity surplus, on the whole, China will achieve a sustainable, healthy economic development" [[18], p.275]. Dang Tieu Binh’s mentality investment priority showed the important role of education: providing advanced, modern knowledge, thinking measure, creativity, accommodating with change of future human resources. On the other hand, in education field, it is necessary to cultivate the capacity of self-learning, applying the knowledge of the educated. Because through the process of learning, human menality is developed through the process of obtaining knowledge, editing, outsourcing, taking advantage of knowledge and creating new knowledge. Without enhancing the selflearning capacity, neither cultivating the capacity to acquire, edit, outsource and exploit mentality information in large scale, human mentality are not enough conditions for the development.

Consequently, education and self-study of knowledge are considered to be the golden key to unlocking mentality treasures. Today, scientists in developing countries also point out that the countries may not be fully industrialized on natural resources and land, as Western countries used to in their history. Historically, it has been possible to rely on superior education and mentality resources, their knowlege to gain relative advantage, participate in the division, cooperate and compete in the world economy, integrate into the global knowledge economy.

Secondly, knowledge is a stimulant for mentality development. Emotion is the nucleus of brainpower, in which the first material that creates mentality is knowledge. Knowledge acts as a motivating and important support for the formation and development of metality. Mentalityr, like the flower of human wisdom, only exists and develops in the realm of fertile knowledge. If we do not accumulate knowledge, constantly learn and absorb new knowledge, creativity in knowledge acquisition, mentality can not develop. Knowledge has a motivational effect with mentality. The curiosity, the passion for seeking knowledge and the desire to create new knowledge, have the effect of strengthening the mind, becoming one of the important motivations for mentality development.

Thirdly, knowledge is the origin of creation - the basic attribute of the mentality. Creativity is considered to be the soul of mentality, but creativity is the result of the concentration and sublimation of knowledge. The characteristics of this day, knowledge is changing, science and technology evolving rapidly, if only purely based learning, absorption and imitation is clearly not enough, even draw the backward. Creation of the new, the soul of the knowledge economy, the creative capacity of the new is the path of development of each region, country, business and individual. Creation of the new is the centralized expression of the mentality - the nucleus of creation. Creativity of the mentality depends on many factors: physiology, education process, nature, mind, 
situation, listed as the examples, but in which the most important is knowledge.

In short, mentality is shaped on the basis of knowledge, knowledge determines the development and creativity of the mentality. Knowledge is equipped through the process of education and self-study of individuals.

\subsubsection{The Role of Mentality in the Knowlege Development}

Firstly, mentality is a tool for absorbing knowledge. Knowledge is seen as an invisible source of human capital. Capacity is the inevitable result of being formed on the basis of individual knowledge accumulation and practice. Brainpower is the nucleus of human capacity, which is manifested through the process of receiving knowledge. Arbitration is considered to be a key factor in gaining knowledge. The biological child says, starting from the mentality, people begin to learn the words have to have memory and observation, listed as the examples, so that in strategy of exploiting and developing intellectual talent of China , was very interested in early education. Based on the results of research into developmental psychology proved, before age 7 , especially before the age of 5 is a "key period" in the mentality development of some people. This is the fastest growing intellectual age, most receptive to education. On the other hand, if one does not grasp the "key period" to conduct education, it will create the most loss, which can not be compensated for in the development of human intellect. The elementary phase is the basic stage for exploiting and developing the intellect, which is the most important period to inherit the knowledge of the forefather, fostering basic skills and capacity [[17], p.175]

Secondly, mentality makes the process of acquiring and creating new knowledge more immersively. Brainpower in the process of acquiring knowledge is not a reproduction of machinery, but rather of receiving, adjusting, processing, and abusing knowledge on the basis of mental factors such as, mind, imagination and creativity form new knowledge. The result is an elevation of the human perception level of the "N nature" of the objective world. Thus, the mentality has created new knowledge, which gives rise to the development of human perception. Pham Ngoc Quang [1] based on the materialist stance of Marxism-Leninism, asserting the great role of knowledge, he claimed that: thanks to the knowledge that forms the economy of saving resources, develop economy depending on human resources with high mentality. Because, as Marx said, nature did not make machines, locomotives, railroads, telegraphs, spinning machines, cellars, listed as the examples. All these were the organs of human brain, created by the human hand, were the forces that materialized by knowledge. So, the dynamics of economic development, social history was the development of human mentality.

Thus, Dang Huu also presented his view to heighten the role of the mentality in the development of the economy. "Social production forces rely on the wealth, overmore, on the mentality and creativity of human" [[5], p.9]. The human creativity is infinite, the resources are limited, the mind-based economy creates great prospects, the infinite possibilities for man to resolve the urgent problems that they have to deal with. In the face of the indispensable development of an economy based on mentality and knowledge resources, with the aim that to solve the challenges, the author suggested that "it is necessary to follow the basis of knowledge and more into mentality resources" [[5], p.11]

Thirdly, the mentality determines the knowledge acquisition. Emotional force is the decisive factor of a dynamic learner, which determines the acquisition and efficiency of human knowledge. One of the manifestations of strong mentality is to handle problems agilely, intelligently, being able to adapt to rapid changes. People who use their knowledge on the basis of accumulated knowledge will enhance their deep understanding. On the basis of this huge memory and deep knowledge, combined with the ability to imagination and unique thinking, individuals will gradually step into the path of mentality creativity

Finally, mentality is the factor that leads knowledge to a "nuclear force" forming the knowledge economy. Thanks to mentality resources, knowledge becomes a "nuclear" resource for economic development, replacing traditional resources: natural resources and cheap labor. As in "Power Shift", Alvin Toffler wrote: No one wants to buy shares for the material possessions of IBM or Apple Computer. The key factor here is not their property neither their equipment, but is their market consumption power and social relationships, organizational capabilities and breakthrough ideas of the minds' their specialists. Software companies do not have large factories and mines, land and grasslands, they just possess high intellectual capital.

Therefore, there is a dialectical relationship of knowledge and mentality, they regulate and govern the development of one another. Knowledge is the basis of the mentality development; the mentality is considered the motivation for the creation of new knowledge, the development of knowledge on higher steps in the perception of objective world. Knowledge is the core factor of the mentality development.

\section{Conclusion}

Nowadays, in a modern economy - knowledge one, knowledge as well as mental ability of workers are considered as significant resources determining development and position of a country among international medium. Thus, a workforce with knowledge and metality become the remarkable competitive factor among countries; knowledge is now the most precious resource controlling all others, and the lever for working capacity, and builds a durable economy. Steady development strategy for countries, in the context where natural resources are rare and toward exhaust, is nothing else but knowledge and intelligent workforce. In the work Power Shift, Alvin Toffler claimed: "The way of power and economy development in XXI century is not something deriving from raw material and human muscle, but the way of applying Mind only. Thus, a failure of understanding role of knowledge in the wealth creation system, followed by delayed performance, will make any economy development strategy unmeaningful, because of the more and more significant attribution of knowledge for economic activities" [[25], p.316]. 
Researching relationship of dialectic relationship between knowledge and mentality shows that each individual should invest extremely in knowledge reserve through education-training, self-studying and creative ability improvement. Education and training are the factors directly determining growth of mentality for the workforce. Social development history has showed the important role of education against mentality growth for the workforce and socio-economic development of a country. Especially, in the global economy by the trend where knowledge becomes an important economy resource, mental working has taken the role of social controller, and with more and more significant role of knowledge, an education of comprehensive knowledge to improve intelligence and creative ability, developing mentality of the workers, has become the key for development of all countries. Each country must promote investment in mentality development through education and training, renewing education toward modern trend and international integration and future vision, developing mental ability, creative thinking and compatible performance.

Presently in Vietnam, education-training investment, lifting up quality of workforce means boosting competition on the international medium. Author Dang Huu emphasized role of education as "creating and multiplying knowledge capital into the most basic production industry" [[31], p.29], forming premium workforce having knowledge and mentality with creative, renewing and fast thinking, sense of applying knowledge in real life to create new values suitable and effective to change of global economy. Failing to form a modern education, knowledge and mentality capital will be not enough to be the inner energy to boost competitive power of Vietnam in facing new waves of global knowledge. Creation and renewing become basic motivations for national economic development. Renewing education for the sake of workforce quality upgrading, focusing on knowledge increase, developing creative ability compatible with quick change of present 4.0 economy, all are urgent. To meet the demand of knowledge workforce, Vietnam should lay an emphasis on education as the most basic production industry for basic requirements of the present global knowledge economy.

Current objective and urgent task is to carry out immediately a comprehensive and coverage revolution for education. Reforming completely and deeply both objectives, content and method in teaching and studying, renewing and developing a universal education system, renewing organization and management method in education are necessary tasks presently. Such work of renewing take the central of converting the traditional education into a modern one which equips knowledge integrated with mentality ability, self-studying ability and compatible ability for the learners to follow up the change as of the digital technology economy like today. Schools is the bridge linking demand of society with ability development of the learners, the place to equip knowledge, train occupational skills, develop creative ability and compatible ability for the learners. On the other hand, in the education development strategy, it is required to build, develop and complete a permanent education system which plays the role of knowledge foundation to flow in and supply knowledge resource for the workforce who is expected to utilize their knowledge meeting demand of global knowledge economy.

Thus, opportunity of development for Vietnam, as well as for any country, lays on education investment - training, improvement of modern science studying ability toward the future; growing mentality: improving and practicing knowledge application, creative thinking, and compatible ability for the workforce to take the power of controlling science-technology revolution in the context of temporary development of the world, claiming position of the country in the international medium.

\section{References}

[1] http://www.chungta.com/nd/tu-lieu-tra-cuu/kinh_te_tri_thuce.html.

[2] Chu Quang Khoi (2009), “Knowledge, a special power”, Manager Magazine, Vol.76 (09), p.44 -45.

[3] Nguyen Thi Xuan (2005), "Knowledge economy and issue of developing human resource of Vietnam for the national industrialization and modernization”, Socio-Science magazine, Vol.6.

[4] Do Thi Thach (2008), "Vietnam Knowledge before the demand of national development and international integration", Political Reasoning Magazine, Vol.6, p.53-55.

[5] Dang Huu (2004), “A Stable Knowledge-based Development”, Political Reasoning Magazine, Vol.11, p.9-13.

[6] Phung Danh Cuong (2013), "The Role of Education and Training in the Development of Vietnam Human Mentality," Magazine of Theoretical Education, Vol. 206 (December), p.56-59.

[7] Bui Van Hue (1996), "On the nature of brainpower capacity," Magazine of Educational Research, Vo.1 9, p.11-12.

[8] Pham Hong Tung \& Pham Ngoc Thach (2009), "Intelligence: Origin, Nature, Structure and Characteristics” Science Magazine, Hanoi National University, Vol.25, p.166 -167.

[9] Pham Thai Viet (2011), "The concept of brainpower capacity" and some reference experiences for the process of developing the strategy of importing and exporting Vietnam's one", Magazine of Philosophy, Vol. 2 (237),

[10] https://thongtinphapluatdansu.edu.vn/2011/09/18/khini\%E1\%BB\%87m-v\%E1\%BB\%91n-tr-tu\%E1\%BB\%87-vm\%E1\%BB\%99t-s\%E1\%BB\%91-kinh-nghi\%E1\%BB\%87mtham-kh\%E1\%BA\%A3o-cho-ti\%E1\%BA\%BFn-trnh-xyd\%E1\%BB\%B1ng-ch/.

[11] Bui Thi Ngoc Lan (2000), "Brainpower capacity with Social Development," Magazine of Theoretical Studies, Vol.7, p.37-39.

[12] Vu Dinh Cu (1997), "Brainpower capacity and breakthrough power", Magazine of Price Market, March Vol.3, p.19-22.

[13] [Hoang Van Luan (2010), "Promoting Vietnam's brainpower capacity for sustainable development", Magazine of Science of National University- Ha Noi , Faculty of Social Sciences and Humanities, Vol. 26, p.156-162.

[14] Pham Minh Hac (2011), "Fostering and using brainpower", Magazine of Educational Sciences, Vol. 64, January, p.2-4.

[15] Nguyen Van Khanh (2012), Vietnam Intelligence Workforce: History, Reality and Vision, National Politics-Truth Press, Hanoi

[16] Ngo Thi Nu (2016), "Vietnam Intelligence Development for International Integration”, Vietnam Science and Society Magazine, Vol. 03, p.37-43.

[17] The Truong (2005), Luggage for Time of Knowledge Economy, Culture and Information Press, Hanoi

[18] Tham Vinh Hoa - Ngo Quoc Dieu (2008), (Translated by Nguyen Nhu Diem), Hightlighting knowledge, Highlighting talents, longterm plan for country improvement, National Politics Press, Hanoi.

[19] Dang Tieu Binh (1993), Literature, People's Publishing House, Vol. 3.

[20] Ministry of Education and Training (1993), Philosophy (Authors), vol. 1, National Political Publishing House, Hanoi.

[21] Karl Marx - Friedrich Engels (1995), Complete Collection (vol.1), National Politics-Truth Press, Hanoi.

[22] Institute of Linguistics (2003), Vietnamese Dictionary, Danang Publishing House. 
[23] Education and Training Ministry of Vietnamese Language and Culture Center (1999), Huge Vietnamese Dictionary, Culture and Information Publishing House.

[24] Dictionary of Philosophy (1986), Progressive Publishing House, Moscow.

[25] Huu Ngoc (1986), Simply Philosophy Dictionary, University and Professional Publishing House, Hanoi.

[26] Alvin Toffler (2002), Power Shift, Khong Duc (translating), Confucianism, The Youth Publishing House, vol. 2, Hanoi.

[27] Alvin Toffler (2002), Power Shift, Khong Duc (translating), Confucianism, The Youth Publishing House, vol. 2, Hanoi.

[28] Ong Van Nam (2013), Knowledge power in the political thought of Alvin Toffler, National Politics-Truth Publishing House, Hanoi.
[29] Education and Training Ministry of Vietnamese Language and Culture Center (1999), Huge Vietnamese Dictionary, Culture and Information Publishing House.

[30] Science - Society - Humanity, Institute of Linguistics, Vietnamese Dictionary, Culture Publishing House, defines mentality as the brain power.

[31] Nguyen Van Dam, (1999), Dictionary of Vietnamese Hermeneutics and Association, Culture and Information Publishing House, Hanoi.

[32] Dang Huu (2005), "Human resources training for the industrialization and modernization based on knowledge in our country today," Magazine of Communist, Vol.4, p.29-33. 